\title{
Education Research: An arts-based curriculum for neurology residents
}

Madaline B. Harrison, MD, and Nicole Chiota-McCollum, MD, MEd

Neurology ${ }^{\circledR}$ 2019;92:e879-e883. doi:10.1212/WNL.0000000000006961

\author{
Correspondence \\ Dr. Harrison \\ MBH3Y@ \\ hscmail.mcc.virginia.edu
}

\begin{abstract}
Objective

To determine the feasibility and educational value of an arts-based curriculum for neurology residents, with the following specific learning objectives: to enhance communication and observational skills, increase awareness of point of view, and deepen appreciation of the narrative content of illness.
\end{abstract}

\section{Methods}

Narrative medicine and visual thinking exercises, adopted from the study of literature and art history, were offered as monthly sessions in the neurology residents' conference schedule. Participants completed an institutional review board-approved anonymous evaluation using a 5-point Likert scale to rate course effectiveness and perform a retrospective pre- and post-selfassessment of communication and visual observation skills. They also provided free text feedback on the course.

\section{Results}

All participants rated the course highly and found the exercises effective in enhancing awareness of language and observational skills. Eighty percent of participants rated their listening and observation skills as above average after participation, which improved from $63 \%$ and $45 \%$, respectively, before the sessions. Comments on the course cited the importance of reflection, focused attention, awareness of multiple perspectives, and appreciation of colleagues.

\section{Conclusions}

Arts-based graduate medical education is feasible and effective in teaching residents to listen and observe more closely. Narrative medicine and visual thinking exercises highlight these skills and promote professional growth, providing an opportunity to reflect and find meaning in clinical work. 


\section{Glossary}

GME = graduate medical education; $\mathbf{U M E}=$ undergraduate medical education.

Medical humanities have been widely adopted in undergraduate medical education (UME), with 143/145 medical schools offering courses in this area. ${ }^{1}$ As with arts-based education in other fields, the scope and methods vary widely. ${ }^{2,3}$ A variety of UME initiatives and their effects on communication, empathy, professional development, and clinical skills have been reported since the initial descriptions in 2001. ${ }^{4,5}$ However, there are few reports of similar programs in graduate medical education (GME). ${ }^{3,6}$

\section{Objective}

To determine the feasibility and educational value of an artsbased curriculum for neurology residents, this pilot project used literature and works of art to teach skills in close listening, reflective writing, visual attention, and interpretation. The curriculum addressed learning objectives relevant to clinical practice: (1) enhancing communication and observational skills; (2) increasing awareness of point of view; and (3) developing appreciation of the narrative content of illness.

\section{Methods}

Narrative medicine and visual thinking exercises are 2 artsbased instructional strategies derived from the study of literature and art history. ${ }^{4,5}$ Monthly sessions using these techniques were included in the residents' conference schedule in 2016-2017. No pre-class preparation was required. Nine narrative medicine workshop sessions began with an exercise in close reading, during which a work of poetry or short fiction was read aloud and discussed. A variety of texts were used, reflecting themes including the medical encounter, the experience of illness and caregiving, and general reflections on work and resilience (table 1). The readings were paired with a reflective writing exercise consisting of free writing to a prompt on a related theme. Residents volunteered to share their writing in pairs, small groups of 3-4, or the whole group. Ground rules for confidentiality were reviewed at each session. The Columbia Reading Guide for Reflective Practice was used in discussion of texts and written responses. ${ }^{7}$ Two sessions adapted from the Clinician's Eye program at the University of Virginia School of Medicine were facilitated by the University of Virginia Fralin Museum's academic curator. ${ }^{8}$ In these slide-based presentations, residents were prompted to look closely at a work of art and generate an inventory of what they noticed and an interpretation of the piece. They discussed how the visual details contributed to that interpretation, drawing analogies to clinical reasoning. In the drawing exercises, residents worked in pairs, one copying an unseen picture based on their partner's verbal description, and then examined the effect of different communication styles on the outcome.
After the final session, residents completed an anonymous evaluation that used a 5-point Likert scale to rate effectiveness of the exercises in teaching communication and visual observation skills and to compare listening and observation skills before and after the course via retrospective pre- and post-selfassessment questions. ${ }^{9}$ The survey also included free text questions (table 2). Participation in the sessions and completion of the course evaluation were optional per institutional policy on educational research. Residents consented to share their evaluations, including free text excerpts. For confidentiality, the Residency coordinator collected consents and evaluations. The project was approved by the Neurology Residency Program Director, the GME Office's Committee on Education, and the Institutional Review Board for Social and Behavioral Sciences.

\section{Results}

All of the 18 adult neurology residents attended the sessions, with $10-12$ residents participating per session (55\%-67\%). The sessions generated lively discussions, although not all residents shared their writing responses. The residents particularly enjoyed the visual arts sessions, posting some drawings in their workroom. Eleven residents (61\%) completed the curriculum evaluation following the final session. Responses were grouped into high/very high (scores of 4 and 5), average (3), and low/very low (2 and 1) and median responses calculated for each item. All the respondents rated the course very highly (median rating of 5). All respondents rated the texts and the class discussion effective in enhancing awareness of language (medians of 4 and 5). Eight respondents $(73 \%)$ rated the writing prompts and discussion of the free writing exercises effective in achieving the same objective (median ratings of 4 ). All respondents rated the discussion of paintings and the drawing exercises very effective in enhancing visual observational skills (median ratings of 5).

The participants' retrospective preintervention and postintervention self-assessments of their listening and visual observation skills showed development in both domains. Precourse listening skills were rated as above average by $63 \%$ of respondents, with $82 \%$ rating listening skills as above average after participation (medians of 4). Pre-course visual observation skills were rated as above average by $45 \%$, while $82 \%$ rated observation skills as above average after participation (medians of 4 ). In addition, $82 \%$ indicated that their understanding of narrative medicine increased from average (median of 3 ) before to above average (median of 4 ) after the sessions. A higher proportion (91\%) reported that their perception of the value of the arts to medical education increased 
Table 1 Curriculum outline

\begin{tabular}{lll}
\hline Session & Materials used & Theme \\
\hline $\mathbf{1}$ & The Things They Carried, Tim O'Brien. Houghton Mifflin, 1990, pp. 13-15 & Work/resilience \\
\hline $\mathbf{3}$ & What the Doctor Said, Raymond Carver. From All of Us: Collected Poems. Harvill Press, 1996 & Medical encounter \\
\hline $\mathbf{4}$ & Mind and Body, William Carlos Williams. From The Doctor Stories. New Directions, 1984, pp. 1 & Medical encounter \\
\hline $\mathbf{5}$ & Listen, Allison Jarvis. Southern Poetry Review, 2005 & Illness and caregiving \\
\hline $\mathbf{6}$ & Any Common Desolation, Ellen Bass. poets.org/poetsorg/poem/any-common-desolation. Accessed on & Work/resilience \\
\hline $\mathbf{7}$ & The Ship Pounding, Donald Hall. From Without: Poems by Donald Hall. Houghton Mifflin, 1998 & Medical encounter; illness and \\
\hline $\mathbf{8}$ & The Clinician's Eye, part 1; 2 hours (reference 8) & Observation/communication \\
\hline $\mathbf{9}$ & Bus, Joan Leegant. Bellevue Literary Review, 2013, 13:43-45 & Illness and caregiving \\
\hline $\mathbf{1 0}$ & The Clinician's Eye, part 2; 1 hour (reference 8) & Observation/communication \\
\hline $\mathbf{1 1}$ & The Engrt, Rafael Campo. Poetry, 2015 & Medical encounter \\
\hline
\end{tabular}

The texts used in each of the narrative sessions are shown, along with the themes they illustrated. The Clinician's Eye sessions used a variety of images from diverse artists and cultures.

from average (median of 3 ) before to above average (median of 5) after the course.

In the free text questions, residents commented on the course and described something they observed in a patient session. Responses are shown in table 2. Comments cited the opportunity for reflection and discussion and noted the importance of reflection, focused attention, awareness of multiple perspectives, and appreciation of colleagues. The visual art sessions stood out as a novel and entertaining experience. Suggestions for improvement included changing the time from Friday afternoon, adding film, and providing materials before the sessions.

\section{Discussion}

Narrative and arts-based techniques may be particularly relevant to the clinical reasoning process used in neurology, which emphasizes history and clinical observation, and to understanding the effect of neurologic illness. ${ }^{6}$ This pilot project developed an arts-based curriculum for neurology residents. The sustained and active participation in the sessions and the high overall rating support the feasibility of using arts-based strategies in a residency curriculum. The time available for each session was limited (about 45 minutes) and due to resident workloads, the group of residents attending each session varied. Despite these logistical challenges, the course evaluation indicates that participants found these artsbased approaches effective in teaching close listening and visual attention skills. In addition, the residents noticed they were better at recognizing multiple points of view in patient encounters. The retrospective pre-post self-assessments and the comments support the relevance to clinical practice and suggest that the residents benefited from their participation.

Our results correspond to previous studies showing that participants value these courses and perceive benefits for communication and professional development. ${ }^{3,5,8}$ Similar to most previous reports, our results are qualitative, and interpretation is limited by small numbers and lack of a control group. The institution requires that participation in educational research must be optional, introducing potential self-selection bias. We chose a retrospective pre-post selfassessment strategy to mitigate the risk of response shift bias, which is encountered in traditional pre-post self-assessment designs when the learner's understanding of the construct being measured changes as a result of the intervention. Although subjective impressions of the course may have confounded the respondents' self-assessment of specific skills, the retrospective pre-post strategy allows for a self-assessment of learning, rather than capturing learner reaction alone. ${ }^{9}$ The results provided useful feedback on residents' perception of the value of this pilot project in developing the skills assessed. An expanded evaluation instrument utilizing both traditional pre-post and retrospective pre-post assessment approaches could be used in future studies to minimize the limitations to validity of each approach taken separately, and might provide additional insights into the effect of the curriculum on clinical reasoning.

Our pilot curriculum differs from prior initiatives using only one text-based or visual arts approach over a brief period in the UME curriculum. We used arts-based strategies from both literature and the visual arts in monthly sessions over a year. Both the textbased and the visual analysis exercises engaged participants in 
Table 2 Curriculum evaluation: free text responses

Question Themes/response examples

1. Give an example of something unexpected you learned while listening to a patient (2/7)

"A misunderstanding of something I thought had [been] correctly communicated but hadn't."

"I learned something very sensitive about the personal life that brought a lot of clarity to her medical history."

2. Give an example of something you noticed while talking with a patient or family (2/7)

"...the way her mother held her head and stroked her hair-and the way this impacted the reporting of her symptoms."

"I noticed by the facial expressions of the family that the patient was not giving accurate history."

\section{What were the strengths of the course? (6/6)}

Opportunity for reflection:

“...discussions re: compassion, integrity, humanistic quality, etc... that we otherwise don't make time for."

“...opportunity, time, and encouragement to reflect on our own patient experience."

"...opportunity to think deeper about some of the intangible aspects of patient care."

"... a place to think about details that are not directly related to patient care, but can impact it, such as the way we communicate."

Break in routine:

"...stepping away from the conventional clinical, non-emotional discussions."

“...a break from our busy days to reflect on various topics."

4. Do particular sessions stand out, and why? (5/7)

5. Describe one "take away" message you discovered from the sessions (7/8)
"Visual sessions were great....able to see meaningful changes in skill immediately."

"All were great. The main strength is getting us all to look at things in different ways...love the painting description that makes you question your assumptions."

"The diversity of writings stood out to me and I especially enjoyed the humanistic parts to it."

"The exercises wherein we drew pictures described to us was particularly good. Helped reinforce importance of communication."

"...the drawing exercises because it made me realize how many things we take for granted."

Reflection:

"Pause to appreciate the gravity and responsibility of practicing medicine."

Attention:

"...listening actively without doing several other tasks simultaneously. Being in the moment."

"...to see and listen not only to what you are medically interested in, but also to what the patient experiences and what they need from you in that moment."

Multiple perspectives:

"People can interpret the exact same situation in many different ways."

"The variety of perspectives that can be taken from the same passage."

Appreciation of colleagues:

"Your fellow residents are your best friends."

"My peers aren't just neurology robots, but they feel things like I do and appreciate aesthetics."

Examples are quoted verbatim from the free text responses. Numbers in parentheses indicate the number quoted relative to the number of responses received in each category. For question 1, 2 of 7 responses are included; the remaining quotes described specific information about the patient such as a job or information concerning a family member. For question 2, 3 additional answers described nonverbal communication among family members, 1 described a tremor in a family member, and 1 was a general observation about the family's reaction to the encounter. For questions $3-5$, answers that duplicated a quoted response were omitted. 
active learning and elicited individual and group responses and perspectives. Consistent with the social constructivist model of contemporary learning theory, this approach allows for reflection and sharing of experiences and perspectives with others to build new knowledge and meaning for the learner. ${ }^{10}$ These active learning approaches are well-suited to the goals of experiencebased learning in the GME setting.

Arts-based GME is feasible and effective. The curriculum we have described is now in its third year, and the monthly sessions use new materials each year in the 3-year residency cycle. Our experience suggests that poems, stories, and works of art can teach residents to listen and observe more closely and to notice what they are hearing and seeing. Arts-based techniques highlight these skills and promote professional growth, offering a rewarding opportunity to reflect and find meaning in our experiences as clinicians. The conceptual framework derived from analysis of arts-based professional education provides a strong rationale for the unique benefits of this approach and offers strategies to design, conduct, and assess arts-based curricula in future studies. ${ }^{2}$

\section{Author contributions}

M. Harrison: drafting/revising the manuscript, data acquisition, study concept or design, analysis or interpretation of data, accepts responsibility for conduct of research and final approval. N. Chiota-McCollum: drafting/revising the manuscript, study concept or design, analysis or interpretation of data, accepts responsibility for conduct of research and final approval.

\section{Acknowledgment}

The authors thank M. Jordan Love, $\mathrm{PhD}$, academic curator at the Fralin Museum, for leading the visual arts sessions;
Andrew Southerland, MD, MS, Program Director in Neurology, for support; and the University of Virginia neurology residents for participation. M.B.H. also thanks the faculty and her fellow students at the Center for Narrative Practice 2015-2016 for providing inspiration and encouragement, particularly Maura Spiegel, $\mathrm{PhD}$, Columbia University Program in Narrative Medicine.

\section{Study funding}

No targeted funding reported.

\section{Disclosure}

The authors report no disclosures relevant to the manuscript. Go to Neurology.org/N for full disclosures.

\section{References}

1. American Association of Medical Colleges. AAMC Curriculum Inventory Report 2016-2017. Available at: aamc.org/initiatives/cir/406462/06a.html. Accessed January 29, 2018.

2. Haidet P, Jarecke J, Admas NF, et al. A guiding framework to maximize the power of the arts in medical education: a systematic review and metasynthesis. Med Educ 2016; 50:320-331.

3. Charon R. Narrative medicine: a model for empathy, reflection, profession and trust. JAMA 2001;286:1897-1902.

4. Dolev JC, Friedlander LK, Braverman IM. Use of fine art to enhance diagnostic skills. JAMA 2001;286:1020-1021.

5. Barber S, Moreno-Leuizamon CJ. Can narrative medicine contribute to the delivery of compassionate care? A review of the literature. Med Humanit 2017;43: 199-203.

6. Alcauskas M, Charon R. Right brain: reading, writing and reflecting. Neurology 2008; 7:891-894.

7. Charon R, Hermann N, Devlin MJ. Close reading and creative writing in clinical education: teaching attention, representation, and affiliation. Acad Med 2016;91: $345-350$.

8. Childress MD, Love MJ. Clinician's eye. In: Hepler L, ed. Changing Views: Art, Contemplation, and Wellness. Charlottesville: Open Grounds, University of Virginia; 2015:29-33.

9. Bhanji F, Gottesman R, deGrave W, Steinert Y, Winer LR. The retrospective pre-post: a practical method to evaluate learning from an educational program. Acad Emerg Med 2012;19:189-194.

10. Torre DM, Daley BJ, Sebastian JL, Elnicki DM. Overview of current learning theories for medical educators. Am J Med 2006;119:903-907. 


\title{
Neurology
}

\author{
Education Research: An arts-based curriculum for neurology residents \\ Madaline B. Harrison and Nicole Chiota-McCollum \\ Neurology 2019;92;e879-e883 \\ DOI 10.1212/WNL.0000000000006961
}

This information is current as of February 18, 2019

\section{Updated Information \&} Services

References

Subspecialty Collections

Permissions \& Licensing

Reprints including high resolution figures, can be found at: http://n.neurology.org/content/92/8/e879.full

This article cites 8 articles, 1 of which you can access for free at: http://n.neurology.org/content/92/8/e879.full\#ref-list-1

This article, along with others on similar topics, appears in the following collection(s):

All Education

http://n.neurology.org/cgi/collection/all_education Methods of education

http://n.neurology.org/cgi/collection/methods_of_education

Information about reproducing this article in parts (figures,tables) or in its entirety can be found online at:

http://www.neurology.org/about/about_the_journal\#permissions

Information about ordering reprints can be found online:

http://n.neurology.org/subscribers/advertise

Neurology ${ }^{\circledR}$ is the official journal of the American Academy of Neurology. Published continuously since 1951, it is now a weekly with 48 issues per year. Copyright (O 2019 American Academy of Neurology. All rights reserved. Print ISSN: 0028-3878. Online ISSN: 1526-632X.

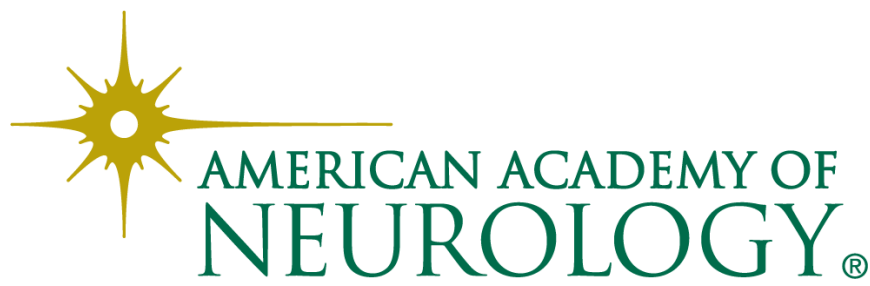

